\title{
Activated carbons treated with sulphuric acid: Catalysts for catalytic wet peroxide oxidation
}

\author{
Helder T. Gomes ${ }^{\text {a,b,* }}$, Sandra M. Miranda ${ }^{\mathrm{b}}$, Maria J. Sampaio ${ }^{\mathrm{b}}$, Adrián M.T. Silva ${ }^{\mathrm{a}}$, Joaquim L. Faria ${ }^{\mathrm{a}}$ \\ ${ }^{a}$ Laboratory of Catalysis and Materials (LCM), Associate Laboratory LSRE/LCM, Department of Chemical Engineering, Faculty of Engineering, University of Porto, \\ Rua Dr. Roberto Frias s/n, 4200-465 Porto, Portugal \\ ${ }^{\mathrm{b}}$ Department of Chemical and Biological Technology, School of Technology and Management, Polytechnic Institute of Bragança, Campus de Santa Apolónia, \\ 5300-857 Bragança, Portugal
}

\section{A R T I C L E I N F O}

Article history:

Available online 18 February 2010

\section{Keywords:}

Activated carbons

Surface chemistry

Sulphur containing functional groups

Thiols

Sulfonic acids

Catalytic wet peroxide oxidation

\begin{abstract}
A B S T R A C T
Different liquid phase thermal treatments were applied to a commercial activated carbon (Norit ROX 0.8) in order to produce modified activated carbons with varying surface chemistry and increased acidic character. Chemical characterization of the prepared materials includes determination of the point of zero charge and evaluation of the concentration and nature of acidic and basic surface functionalities by acid/base titrations and temperature programmed desorption. The prepared materials were used as catalysts in the catalytic wet peroxide oxidation of the acid dye Chromotrope $2 \mathrm{R}$ in order to assess their removal efficiency. The relationship between the surface chemistry and efficiency for dye removal is discussed. As expected, decreasing acidity of the catalysts surface will correlate with increasing dye conversion. Unexpectedly, treatment with sulphuric acid leads to a very high yield of dye removal which falls out of the previous correlation. This was explained in terms of the introduction of sulphur containing groups on the carbon surface, which promotes the surface interaction between the pollutant and hydrogen peroxide: higher production of hydroxyl radicals close to the pollutant leads to improved dye removal. In addition, reutilization studies show that the catalyst prepared by sulphuric acid treatment is able to keep its performance in successive runs.
\end{abstract}

() 2010 Elsevier B.V. All rights reserved.

\section{Introduction}

The research and development of efficient wastewater treatment technologies received in recent years great attention from the scientific community, especially in the case of the so called advanced oxidation processes (AOP) [1,2]. Among all the possibilities, the Fenton process is widely recognized as a low cost AOP, able to operate at atmospheric pressure and room temperature with a simple technology [3,4]. The high efficiency in the degradation of organic pollutants is due to the participation of hydroxyl radicals, very reactive oxidizing species resulting from the catalytic decomposition of hydrogen peroxide in the presence of $\mathrm{Fe}(\mathrm{II})$. However, due to transference of the iron into the treated waters, additional separation steps are needed to remove it. To solve this drawback, several efforts have been done to develop heterogeneous catalysts containing non-leaching iron, which will be able to generate the desired hydroxyl radicals [5-9]. Nevertheless, the

\footnotetext{
* Corresponding author at: Polytechnic Institute of Bragança, Department of Chemical and Biological Technology, Campus de Santa Apolonia, 5300-857 Bragança, Portugal. Tel.: +351 273303 110; fax: +351 273313051.

E-mail address: htgomes@ipb.pt (H.T. Gomes).
}

problem still remains, since many of these developed catalysts are barely stable and do leach under process operating conditions. An alternative strategy is to completely eliminate the presence of iron through the use of heterogeneous catalysts with no metallic phase, but with the adequate ability to promote the formation of the oxidizing agent. Recent results show that activated carbons are efficient in the degradation of some dissolved organic pollutants in the presence of hydrogen peroxide [10-13], providing that the carbon surface possesses suitable chemical properties. Activated carbons are known catalysts for hydrogen peroxide decomposition through the formation of hydroxyl radicals. Therefore, it seems logical to use these radicals in the degradation of organic pollutants adsorbed and concentrated over activated carbons.

Activated carbons, and carbon materials in general, are very flexible materials, since their textural and surface chemical properties can be easily tuned by proper chemical and physical treatments [14,15]. Those properties have been thoroughly studied by our group in order to produce suitable catalytic materials for a wide range of specific applications, in particular activated carbons, carbon xerogels and carbon nanotubes for catalytic wet air oxidation [16-18].

When conventional treatments are used to modify the surface chemistry, the removal of anionic dyes is mainly governed by the 
acid/base character of the carbon surface: higher basic character favouring the efficiency of the material. To our knowledge, in this work we demonstrate for the first time the unprecedented performance of acidic activated carbons, after a liquid phase thermal treatment with sulphuric acid, in the catalytic wet peroxide oxidation of the anionic azo dye Chromotrope $2 \mathrm{R}$ (C2R). This dye was selected as model pollutant because of its current use in the textile industry, its chemical structure and finally, because the removal of colour from textile effluents has been an issue of very active research in the field of wastewater treatment, due to the high environmental and social problems associated with this type of pollution.

\section{Materials and methods}

\subsection{Reactants}

Chromotrope $2 \mathrm{R}\left(\mathrm{C}_{16} \mathrm{H}_{10} \mathrm{~N}_{2} \mathrm{Na}_{2} \mathrm{O}_{8} \mathrm{~S}_{2}, \mathrm{Mr} 468.39\right.$ [4197-07-3], Colour Index Acid Red 29, molecular structure as shown in Scheme 1) was obtained from Fluka. Hydrogen peroxide (30\%, w/v), hydrochloric acid (37 wt.\%), sodium hydroxide (98wt.\%) and sodium chloride (99.5 wt.\%) were obtained from Panreac. Sulphuric acid (96-98 wt.\%) was obtained from Riedel-de-Haën. All chemicals were used as received without further purification. Distilled water was used throughout the work.

\subsection{Activated carbons}

Four different activated carbon samples were considered in this work: the activated carbon Norit ROX 0.8 (AC), as it is, and chemically modified by liquid phase treatments with hydrogen peroxide (ACHP), sulphuric acid (ACSA) and nitric acid (ACNA). Nitric acid oxidation was carried out boiling $10 \mathrm{~g}$ of $A C$ in $200 \mathrm{~mL}$ of $5 \mathrm{M}$ nitric acid solution for $3 \mathrm{~h}$. The treatment with hydrogen peroxide was performed wetting $10 \mathrm{~g}$ of AC with $200 \mathrm{~mL}$ of hydrogen peroxide solution $30 \%(\mathrm{w} / \mathrm{v})$ at room temperature for $24 \mathrm{~h}$. In sulphuric acid oxidation, $10 \mathrm{~g}$ of $\mathrm{AC}$ were immersed in $200 \mathrm{~mL}$ of $5 \mathrm{M}$ acid solution for $3 \mathrm{~h}$ at $353 \mathrm{~K}$. After the liquid phase treatments, all samples were thoroughly washed with distilled water until the neutrality of the rinsing waters and further dried in oven for $18 \mathrm{~h}$ at $383 \mathrm{~K}$.

\subsection{Catalysts characterization}

Textural characterization was performed in a Quantachrome NOVA 4200e $\mathrm{N}_{2}$ adsorption analyser. The surface chemistry of the carbon materials was characterized by (i) their point of zero charge (PZC), determined by $\mathrm{pH}$ drift tests; (ii) the concentration of acidic and basic sites, using titration techniques and (iii) the nature of the oxygen containing groups on the materials surface, identified by temperature programmed desorption (TPD).

PZC was determined by $\mathrm{pH}$ drift tests following the procedure described elsewhere [19]. Five solutions with varying initial $\mathrm{pH}$ were prepared using $0.01 \mathrm{M}$ or $0.1 \mathrm{M} \mathrm{HCl} / \mathrm{NaOH}$ solutions and $\mathrm{NaCl}$ $(0.01 \mathrm{M})$ as electrolyte. $50 \mathrm{~mL}$ of each solution was contacted with $0.15 \mathrm{~g}$ of carbon sample and the suspension left under stirring for

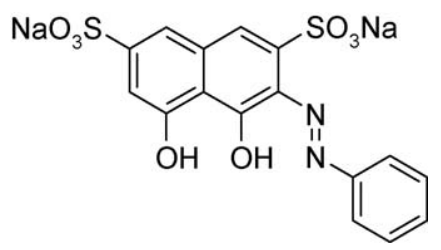

Scheme 1. Molecular structure of Chromotrope 2R.
$24 \mathrm{~h}$ and the equilibrium $\mathrm{pH}$ measured. The PZC value of each carbon sample was determined intercepting the obtained final $\mathrm{pH}$ versus initial $\mathrm{pH}$ curve with the straight line final $\mathrm{pH}=$ initial $\mathrm{pH}$.

The concentration of acidic sites at the materials surface was determined adding $0.2 \mathrm{~g}$ of each catalyst sample to $25 \mathrm{~mL}$ of a $0.02 \mathrm{M} \mathrm{NaOH}$ solution. The resulting suspension was left under stirring for $48 \mathrm{~h}$ at room temperature. After filtration to remove the solid material, the residual $\mathrm{HO}^{-}$was titrated with a $0.02 \mathrm{M} \mathrm{HCl}$ solution. The concentration of acid sites at the carbon surface was calculated subtracting the moles of $\mathrm{NaOH}$ at the end of stirring from the moles of $\mathrm{NaOH}$ initially present in the suspension and dividing this value by the mass of material. The concentration of basic sites was determined in a similar way, this time adding the carbon sample to a $0.02 \mathrm{M} \mathrm{HCl}$ solution and titrating the resultant solution after stirring and filtration with a $0.02 \mathrm{M} \mathrm{NaOH}$ solution. Phenolphthalein was used as indicator in the titrations.

TPD analysis was performed in a fully automated AMI-200 Catalyst Characterization Instrument (Altamira Instruments), equipped with a quadrupole mass spectrometer (Dymaxion, Ametek). The catalyst sample $(0.10 \mathrm{~g})$ was placed in a U-shaped quartz tube inside an electrical furnace and heated at $5 \mathrm{~K} \mathrm{~min}^{-1}$ up to $1373 \mathrm{~K}$ using a constant flow rate of helium $\left(25 \mathrm{~mL} \mathrm{~min}^{-1}\right.$, STP). The mass signals $m / z=28,44,48$ and 64 were monitored during the thermal analysis. The amounts of $\mathrm{CO}$ and $\mathrm{CO}_{2}$ were calibrated at the end of each analysis with pure $\mathrm{CO}$ and $\mathrm{CO}_{2}$ gases, with main mass signals $m / z$ of 28 and 44, respectively. After acquisition, the mass signal $m / z=28$ monitored during the thermal analysis for CO was corrected in order to eliminate the influence of $\mathrm{CO}_{2}$ on $\mathrm{CO}$ evolution, since one of the fragments in the mass spectra of $\mathrm{CO}_{2}$ occurs at $m / z=28$. The mass signal corresponding to the release of SO $(m / z=48)$ was also monitored, since it is an important fragment in the mass spectra of $\mathrm{SO}_{2}$, with a peak intensity of $49 \%$ to that of $\mathrm{SO}_{2}$ [20]. The amounts of $\mathrm{SO}_{2}$ were calibrated with sulphanilamide, which releases $\mathrm{SO}_{2}$ upon thermal degradation. After the treatment of the acquired data, the TPD spectra of $\mathrm{CO}, \mathrm{CO}_{2}$ and $\mathrm{SO}_{2}$ (in $\mu \mathrm{mol} \mathrm{g}-1 \mathrm{~s}^{-1}$ ) were obtained.

\subsection{Catalytic runs}

All the oxidation reactions were performed in a $500 \mathrm{~mL}$ wellstirred glass reactor equipped with a condenser, a $\mathrm{pH}$ measurement electrode, a temperature measurement thermocouple and a sample collection port. The reactor was heated by immersion on a thermostatic water bath, monitored by a temperature controller. Agitation of the reaction mixture was provided by a magnetic stirrer.

In a typical oxidation run the reactor was loaded with $250 \mathrm{~mL}$ of water pollutant solution (C2R with a concentration of $100 \mathrm{mg} / \mathrm{L}$ ) and for CWPO runs the desired load of catalyst $(0.5 \mathrm{~g} / \mathrm{L})$. Then, the reactor was heated to the desired reaction temperature $(323 \mathrm{~K})$. After stabilization of temperature, the solution $\mathrm{pH}$ was adjusted to three using 1.0 or $0.1 \mathrm{M}$ solutions of $\mathrm{NaOH}$ or $\mathrm{H}_{2} \mathrm{SO}_{4}$. A calculated volume of hydrogen peroxide $(6 \%, \mathrm{w} / \mathrm{v})$ was injected into the system, before starting the reaction, to give the desired concentration inside the reactor $(34.6 \mathrm{mM}$, corresponding to approximately five times the stoichiometric amount needed to completely mineralize $\mathrm{C} 2 \mathrm{R}$ ). In order to assess the contribution of adsorption on the removal of the pollutant, blank experiments were performed under the same operating conditions without added hydrogen peroxide.

\subsection{Analytical methods}

Small aliquots were withdrawn periodically from the reactor to be further analyzed for azo dye concentration, determined by UVvis spectrophotometry (Varian Cary 50 Scan). The maximum 
absorbance of C2R was found at $509 \mathrm{~nm}$ wavelength by recording its spectra at different concentrations in the range $200-800 \mathrm{~nm}$ and associated to the chromophoric group (the azo bond $-\mathrm{N}=\mathrm{N}-$ ). Hydrogen peroxide concentration in decomposition experiments was monitored by permanganometry [21]. Total organic carbon (TOC) was measured in a TOC analyzer (Shimadzu 5500A). This equipment first determines total carbon (TC) by sample combustion at $973 \mathrm{~K}$ over a Pt catalyst bed and then total inorganic carbon (TIC) using phosphoric acid. TOC was calculated discounting TIC from TC. For the analytical determinations of azo dye concentration and TOC, three values with variance $<3 \%$ were considered.

\section{Results and discussion}

\subsection{Catalysts characterization}

The textural characterization of the carbon materials studied in this work is given in Table 1 in terms of specific surface area $\left(S_{\mathrm{BET}}\right)$, non-microporous surface area $\left(S_{\mathrm{MES}}\right)$ and micropore volume $\left(V_{\mathrm{MIC}}\right)$. As observed, the treatments performed to the AC material with hydrogen peroxide, sulphuric acid and nitric acid do not affect in a great extent the textural properties of the original material, which can be considered similar. The acid/base character of the tested materials, determined by PZC measurements and by acid/base titrations, is also shown in Table 1.

The original AC possesses twice the concentration of basic functionalities $\left(540 \mu \mathrm{mol} \mathrm{g}^{-1}\right.$ ) in comparison to acidic functionalities $\left(270 \mu \mathrm{mol} \mathrm{g}^{-1}\right)$. While the treatment of AC with hydrogen peroxide resulted in a material with a slightly higher concentration of acidic functionalities, the treatment with sulphuric acid produced a material with a markedly acidic character, the concentration of acidic surface groups $\left(800 \mu \mathrm{mol} \mathrm{g}^{-1}\right)$ being found to be 2.7 times higher than the concentration of basic surface groups $\left(300 \mu \mathrm{mol} \mathrm{g}^{-1}\right.$ ). When nitric acid was used, the acidic character of the obtained material was even stronger, with the concentration of acidic surface groups $\left(840 \mu \mathrm{mol} \mathrm{g}^{-1}\right)$ found to be 7.6 times higher than the concentration of basic surface groups $\left(110 \mu \mathrm{mol} \mathrm{g}^{-1}\right)$. The PZC values of all materials are in accordance with their acid/base properties, lower PZC corresponding to higher acidic character.

The TPD spectra of $\mathrm{CO}, \mathrm{CO}_{2}$ and $\mathrm{SO}_{2}$ are shown in Fig. 1 and the corresponding concentration of the monitored species gathered in Table 2, allowing the comparison of the total amounts of functional groups introduced on the surface of the carbon samples subjected to the different liquid phase treatments. The TPD results also allow the identification and quantification of the functional groups present on the materials surface by peak assignment and deconvolution procedures, as described elsewhere [22,23]. The release of $\mathrm{CO}$ (Fig. 1(a)) was attributed to carboxylic anhydrides, phenols and quinones. The release of $\mathrm{CO}_{2}$ (Fig. 1(b)) was attributed to carboxylic anhydrides, lactones and carboxylic acids. In the case of carboxylic acids, both low temperature and high temperature decomposing groups were considered, to better describe the release of $\mathrm{CO}_{2}$ at temperatures between 400 and $700 \mathrm{~K}$. The release of $\mathrm{SO}_{2}$ (Fig. 1(c)) between 500 and $650 \mathrm{~K}$ was attributed to thiol and sulfonic acid groups [24]. The decomposition temperature of
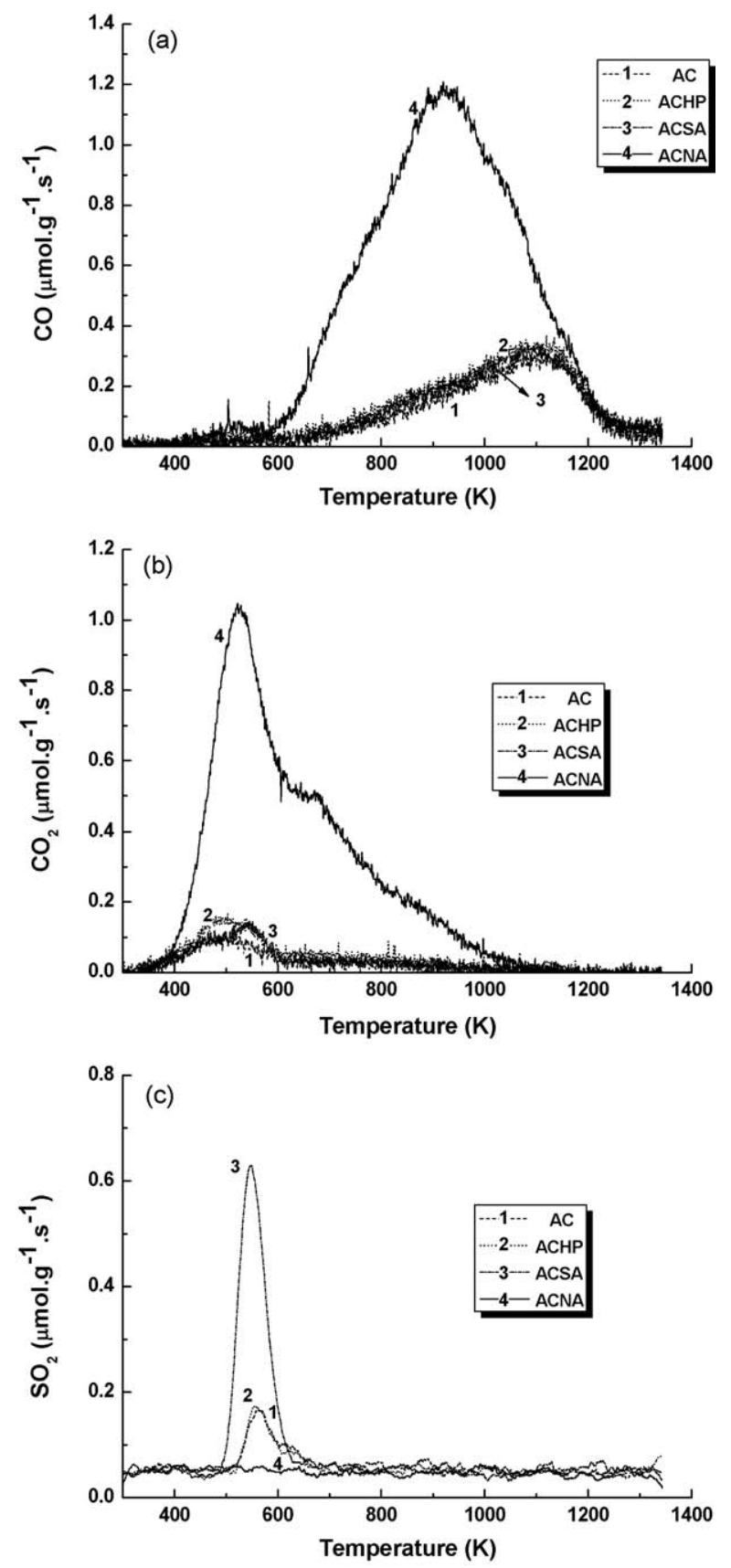

Fig. 1. TPD spectra of the carbon materials subjected to different liquid phase treatments: (a) $\mathrm{CO}$, (b) $\mathrm{CO}_{2}$ and (c) $\mathrm{SO}_{2}$ evolution with temperature.

other sulphur containing functional groups, such as sulphoxides, sulphones and sulphides ranges between 700 and $1000 \mathrm{~K}$ [24]. These groups are unlikely to be present on the surface of the activated carbon samples, since were not observed in the $\mathrm{SO}_{2}$

Table 1

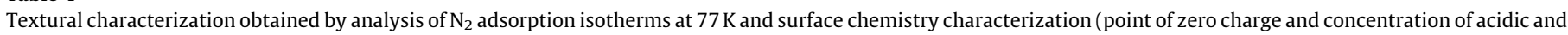
basic active sites) of the prepared carbon materials.

\begin{tabular}{|c|c|c|c|c|c|c|}
\hline Catalyst & $S_{\text {BET }}\left( \pm 10 \mathrm{~m}^{2} \mathrm{~g}^{-1}\right)$ & $S_{\mathrm{MES}}\left( \pm 10 \mathrm{~m}^{2} \mathrm{~g}^{-1}\right)$ & $V_{\text {MIC }}{ }^{\mathrm{a}}\left( \pm 0.01 \mathrm{~cm}^{3} \mathrm{~g}^{-1}\right)$ & $\mathrm{PZC}( \pm 0.1)$ & Acidity $( \pm 10 \mu \mathrm{mol} / \mathrm{g})$ & Basicity $( \pm 10 \mu \mathrm{mol} / \mathrm{g})$ \\
\hline $\mathrm{AC}$ & 850 & 190 & 0.33 & 7.6 & 270 & 540 \\
\hline ACHP & 850 & 180 & 0.33 & 6.8 & 390 & 510 \\
\hline ACSA & 840 & 180 & 0.32 & 5.8 & 800 & 300 \\
\hline ACNA & 830 & 220 & 0.29 & 2.0 & 840 & 110 \\
\hline
\end{tabular}

\footnotetext{
a Microporosity upper limit is $2 \mathrm{~nm}$.
} 
Table 2

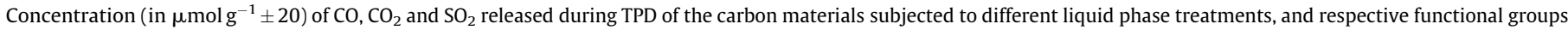
determined by deconvolution.

\begin{tabular}{|c|c|c|c|c|c|c|c|c|c|c|}
\hline Catalyst & $\mathrm{CO}$ & $\mathrm{CO}_{2}$ & $\mathrm{SO}_{2}$ & Phenol & Quinone & Anhydride & Lactone & Carboxylic & Thiol & Sulfonic \\
\hline $\mathrm{AC}$ & 1200 & 380 & 120 & 320 & 820 & 80 & 20 & 220 & 60 & 40 \\
\hline ACHP & 1480 & 480 & 80 & 460 & 900 & 80 & 60 & 340 & 60 & 40 \\
\hline ACSA & 1360 & 420 & 460 & 380 & 820 & 100 & 40 & 260 & 400 & 40 \\
\hline ACNA & 5140 & 3040 & 0 & 3360 & 1140 & 620 & 160 & 2300 & 0 & 0 \\
\hline
\end{tabular}

spectra. Table 2 also summarizes the concentration of the different functional groups present on the carbon materials surface.

From the observation of the TPD spectra of $\mathrm{CO}$ and $\mathrm{CO}_{2}$ (Fig. 1(a) and (b)) it is clear that the thermal decomposition of ACNA results in a much higher release of $\mathrm{CO}$ and $\mathrm{CO}_{2}$ species, when compared with the original AC. The concentration of the evolved $\mathrm{CO}$ and $\mathrm{CO}_{2}$ increased from 1200 to $380 \mu \mathrm{mol} \mathrm{g}^{-1}$, respectively, for the AC, to 5140 and $3040 \mu \mathrm{mol} \mathrm{g}^{-1}$, for the ACNA. This strong increase in the concentration of functional groups upon nitric acid oxidation, as observed in Table 2, is mainly attributed to the presence of large amounts of surface acidic carboxylic groups $\left(\mathrm{CO}_{2}\right.$ peak maxima $510-720 \mathrm{~K}$ ) and phenols (CO peak maxima 900-990 K) on the material $[22,23,25]$. The introduction of functional groups decomposing as $\mathrm{CO}$ and $\mathrm{CO}_{2}$ on the surface of the materials ACHP and ACSA is rather modest. This is in agreement with the slight increase of the ACHP acidity (when compared with AC), but not with the significant increase of ACSA acidity (Table 1). Following the $\mathrm{SO}_{2}$ concentration development in the TPD spectra (Fig. 1(c)), it is clear the release of these groups on ACSA when compared with the other materials. The peak area of $\mathrm{SO}_{2}$ increased from $120 \mu \mathrm{mol} \mathrm{g}^{-1}$ in the AC, to $460 \mu \mathrm{mol} \mathrm{g}^{-1}$ in the ACSA. This is mainly due to the introduction of thiol groups on the surface upon sulphuric acid treatment (Table 2), which decompose releasing $\mathrm{SO}_{2}$ species [24]. It is worth to note that the original AC possesses a non-negligible concentration of sulphur containing surface groups, which are removed by the nitric acid treatment but not much affected by the hydrogen peroxide. In summary, the differences observed in the acid/base characteristics given in Table 1 are mainly due to the increase in the concentration of carboxylic acid and phenol groups in the ACNA material and to the increase in the concentration of sulphur containing groups in the ACSA.

\subsection{Catalytic wet peroxide oxidation}

The $\mathrm{C} 2 \mathrm{R}$ removal results obtained with the activated carbon materials, either in the adsorption and reaction experiments, are given in Fig. 2.

From Fig. 2(a), it is observed that the contribution of adsorption in the removal of $\mathrm{C} 2 \mathrm{R}$ is not negligible and that depends on the carbon sample used, more specifically on their surface chemistry, since their textural properties were found to be similar $\left(S_{\mathrm{BET}} \approx 840 \mathrm{~m}^{2} \mathrm{~g}^{-1}\right)$. For each carbon sample it is observed that the introduction of hydrogen peroxide in the system clearly increases $\mathrm{C} 2 \mathrm{R}$ removal due to reaction. This effect is particularly noticeable for the ACSA, with the order of removal being ACSA $>$ AC $>$ ACHP $>$ ACNA. The relative concentration of ACSA after $150 \mathrm{~min}$ of reaction is $22 \%$ lower than the observed for the worst catalyst (ACNA). The same order was observed regarding TOC removal and the respective difference in terms of TOC between ACSA and ACNA after 150 min was of 16\%, indicating that mineralization products are obtained from C2R removal. The initial $\mathrm{C} 2 \mathrm{R}$ adsorption and reaction removal rates, defined as mass of C2R removed per minute and per mass of adsorbent or catalyst are plotted against the corresponding PZC values in Fig. 2(b). If was not for ACSA there would be perfect correlation between the surface chemistry and both initial adsorption and reaction rates. ACSA does not only provides a better adsorption of $\mathrm{C} 2 \mathrm{R}$, but also reacts much faster after the adsorption process with relation to the expected based on the other systems.

The initial adsorption rates $\left(\mathrm{mg}_{\mathrm{C} 2 \mathrm{R}} \mathrm{g}^{-1} \mathrm{~min}^{-1}\right)$ change from 0.04 to 0.25 , for ACNA and ACSA samples, respectively. The low adsorption performance of ACNA is related to its PZC value (2.0) and to the fact that C2R in solution is found in an anionic form. Since PZC is lower than the solution $\mathrm{pH}$ of 3 , the carbon surface will be negatively charged and the anionic dye will suffer repulsion forces when close to the activated carbon surface, thus inhibiting adsorption [26]. When the PZC is higher than the solution $\mathrm{pH}$, the surface of activated carbon will be positively charged, favouring the adsorption of the anionic dye by electrostatic attraction [26]. The influence of PZC of activated carbons in the adsorption of anionic and cationic dyes is well documented in the literature [27]. In the case of anionic dyes in solutions at $\mathrm{pH}=3$, adsorption normally increases with increasing PZC. The same behaviour is observed in our adsorption results, except for ACSA (Fig. 2(b)). The nature of groups introduced on the carbon surface when treated with sulphuric acid is rather different than those introduced upon the other conventional treatments (hydrogen peroxide treatment and nitric acid oxidation), thiol and sulphonic acids prevailing over carboxylic acid, carboxylic anhydrides, lactones, phenol and quinone groups [24]. The higher initial adsorption rate observed
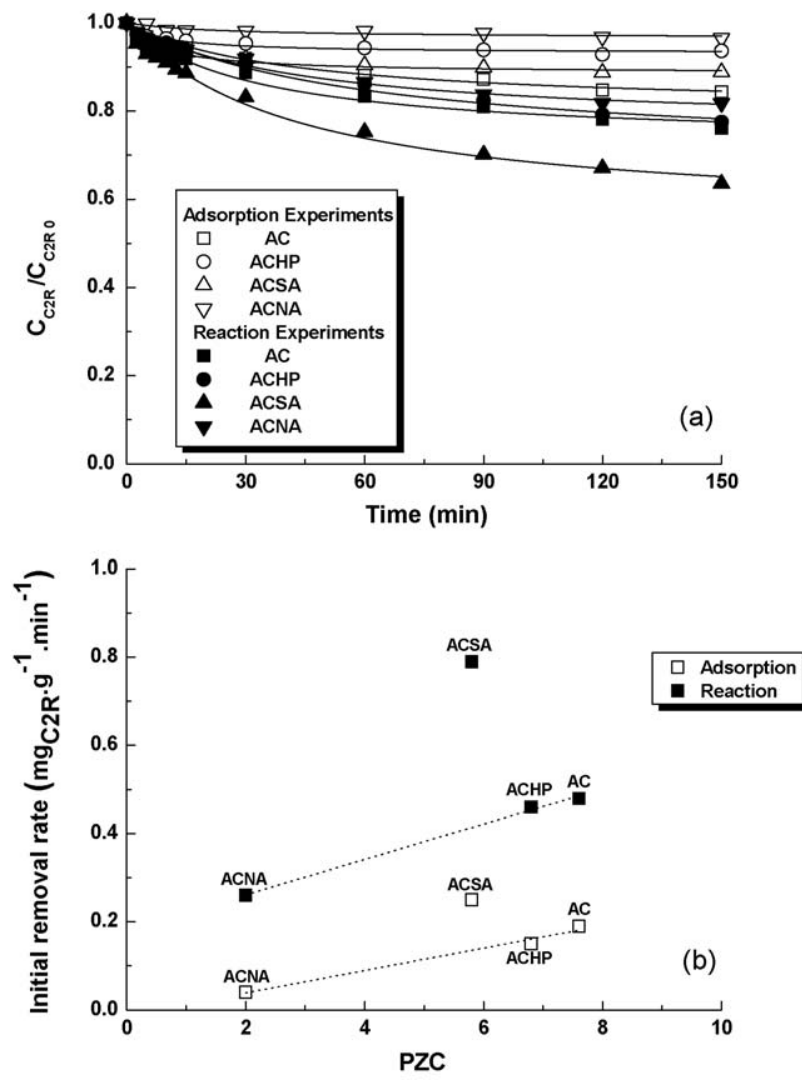

Fig. 2. Removal of $C 2 R$ from the aqueous solution in adsorption and reaction experiments at $323 \mathrm{~K}$ : (a) concentration decay curves and (b) initial removal rates, as function of PZC values of the different activated carbons. 
when using the sample treated with sulphuric acid may then be explained in terms of the presence of sulphur containing groups on the surface, increasing its affinity to the organic substrate. An attractive interaction (e.g. by group interchange) may be developed due to the common sulphurous groups present simultaneously in the solid surface and in the soluble molecule. It is noticeable to observe that adsorption contributes to $1 / 3$ of the total removal rates in oxidizing conditions.

Regarding the reaction experiments, the highest initial reaction rate was obtained with ACSA $\left(0.79 \mathrm{mg}_{\mathrm{C} 2 \mathrm{R}} \mathrm{g}^{-1} \mathrm{~min}^{-1}\right)$, while the lowest was obtained with ACNA $\left(0.26 \mathrm{mg}_{\mathrm{C} 2 \mathrm{R}} \mathrm{g}^{-1} \mathrm{~min}^{-1}\right)$. Once again, there is a correlation between $\mathrm{C} 2 \mathrm{R}$ removal rates and the acidic nature of the activated carbons AC, ACHP and ACNA (Fig. 2(b)), which is not adequate to describe the results obtained with the carbon containing sulphur functional groups (ACSA). These groups seem to play an important role in pollutant removal. This may be due, in one hand, to their hydrophilic character, which enable a more intimate contact between the aqueous solution and the ACSA carbon surface, thus increasing the corresponding adsorption of $\mathrm{C} 2 \mathrm{R}$ and hydrogen peroxide molecules, essential steps for further reaction of C2R with hydroxyl radicals generated nearby at the catalyst surface, and, in other hand, to the presence of large amounts of thiol groups (Table 2), which react with hydrogen peroxide, generating hydroxyl radicals according to the equation:

$\mathrm{SH}+\mathrm{H}_{2} \mathrm{O}_{2} \rightarrow \mathrm{HO}^{-}+\mathrm{HO}^{\bullet}+\mathrm{SH}^{+}$

In order to evaluate the activity of each carbon sample for the decomposition of hydrogen peroxide, decomposition experiments were carried out under the same conditions described in the experimental section, but without added C2R. The results are shown in Fig. 3, evidencing that the decomposition of hydrogen peroxide is strongly influenced by the carbon catalyst used, and consequently, by their surface chemistry. Since the decomposition of hydrogen peroxide involves the generation of hydroxyl radicals, an efficient catalyst is the one showing simultaneously high activity for hydrogen peroxide decomposition and for the reaction between generated hydroxyl radicals and adsorbed pollutant. It is worth notice that the activity of the tested catalysts for hydrogen peroxide decomposition increases fairly in the same order as the activity found previously for $\mathrm{C} 2 \mathrm{R}$ removal, i.e., ACSA $>$ AC $>$ ACHP $>$ ACNA, thus allowing to conclude that nitric acid and hydrogen peroxide treatments decrease the activity of the original AC while the presence of sulphur containing groups on the surface of the carbon samples will slightly benefit the reaction (as shown in Fig. 3). In addition, the activated carbon treated with sulphuric acid increases

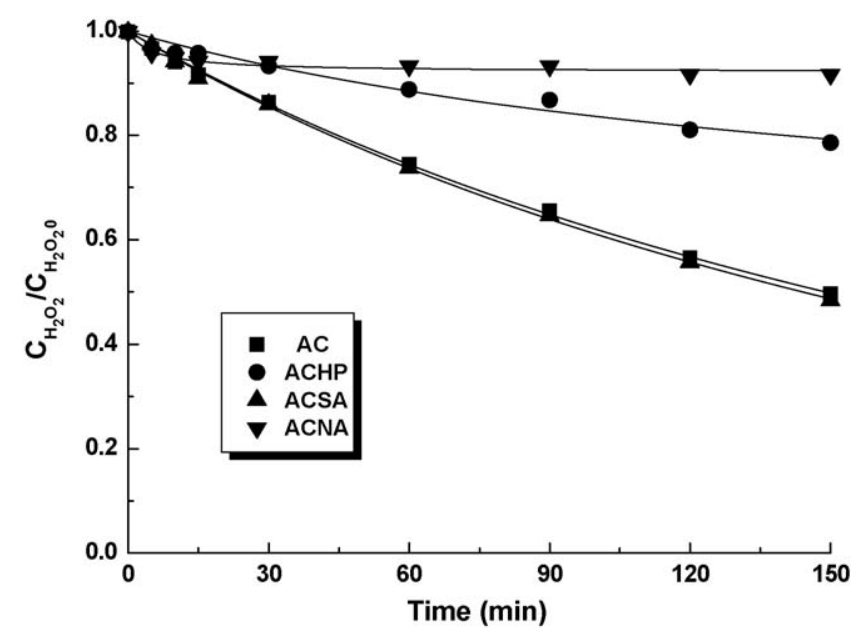

Fig. 3. Hydrogen peroxide decomposition experiments at $323 \mathrm{~K}$ over carbon catalysts with varying surface chemistry. the efficiency of the reaction between the generated hydroxyl radicals and adsorbed C2R (as inferred from Fig. 2).

The capacity of ACSA to be used in continuous experiments was assessed by reutilization studies. After an oxidation run, the catalyst was recovered from the solution, washed with water until neutrality of the rinsing waters and dried in oven at $383 \mathrm{~K}$ for $18 \mathrm{~h}$. The recovered catalyst was then used in a new experiment with fresh reactants under the same conditions described for the first run in the experimental section. The recovery procedure was repeated until the original ACSA catalyst was used four times. The results obtained are shown in Fig. 4 for consecutive runs, in terms of relative concentration of C2R versus time (Fig. 4(a)) and of initial reaction rate (Fig. 4(b)) for each particular run. From the relative concentration decay curves, it is observed that the $C 2 R$ removal extent decreases noticeably from the first to the second run, similar removal behavior being observed in the following runs. From the initial reaction rate values, it is confirmed that the highest initial reaction rate was achieved with the fresh catalyst $\left(0.79 \mathrm{mg}_{\mathrm{C} 2 \mathrm{R}} \mathrm{g}^{-1} \mathrm{~min}^{-1}\right)$, decreasing this value about $25 \%$ for the second run, which then remained constant around $0.59 \mathrm{mg}_{\mathrm{C} 2 \mathrm{R}} \mathrm{g}^{-1} \mathrm{~min}^{-1}$ for the subsequent runs (up to four). If we take into consideration that, in the first run, adsorption contributes with $1 / 3$ to the total $C 2 \mathrm{R}$ removal, the loss of removal activity from the first to the following runs may be explained by adsorption of organic matter at the surface of ACSA, which was not completely desorbed after the reconditioning of the catalyst. Then, at the beginning of the second run, the catalyst surface already contains some adsorbed pollutant, implying that the initial removal of C2R due to adsorption does not occur in the same extent as in the first run. Therefore, the observed removal is
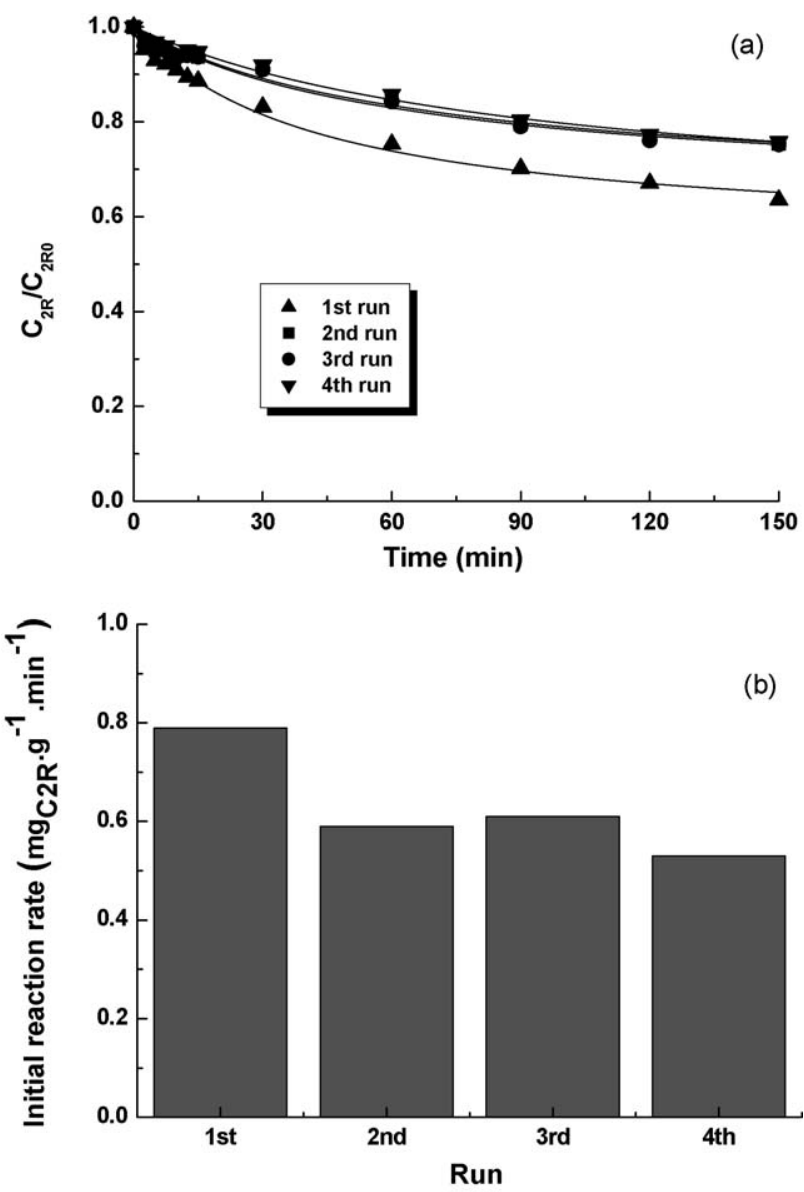

Fig. 4. Removal of $C 2 R$ by $C W P O$ in sequential experiments at $323 \mathrm{~K}$ in the presence of ACSA (a) concentration decay curves and (b) initial removal rates. 
mainly due to adsorbed $\mathrm{C} 2 \mathrm{R}$ degradation by reaction with hydroxyl radicals generated at the catalyst surface from the decomposition of adsorbed hydrogen peroxide.

\section{Conclusions}

Activated carbons treated with sulphuric acid show an unexpected efficiency in catalytic wet peroxide oxidation of a model anionic azo dye.

The probe dye molecule adsorbs better and reacts faster in the presence of the AC thermally treated with sulphuric acid. This results from enhanced affinity between the reactant and the catalyst surface due to the presence of surface groups containing sulphur. In this way, the dye is efficiently adsorbed close to the centers where the hydroxyl radicals are generated, promoting its synergistically degradative oxidation.

Reutilization studies show that the catalyst prepared by sulphuric acid treatment, after an initial non-significant lost of activity is able to keep its performance in successive runs.

\section{Acknowledgements}

Fundação para a Ciência e a Tecnologia and FEDER through FEDER/POCI/2010 and REEQ/1106/EQU2005. AMTS acknowledges the financial support from POCI/N010/2006. Norit for supplying Norit ROX 0.8 .

\section{References}

[1] A.S. Stasinakis, Use of selected advanced oxidation processes (AOPs) for wastewater treatment - a mini review, Glob. Nest. J. 10 (2008) 376-385.

[2] C. von Sonntag, Advanced oxidation processes: mechanistic aspects, Water Sci. Technol. 58 (2008) 1015-1021.

[3] M. Pérez, F. Torrades, J.A. García-Hortal, X. Doménech, J. Peral, Removal of organic contaminants in paper pulp treatment effluents under Fenton and photo-Fenton conditions, Appl. Catal. B 36 (2002) 63-74.

[4] J.J. Pignatello, E. Oliveros, A. MacKay, Advanced oxidation processes for organic contaminant destruction based on the Fenton reaction and related chemistry, Crit. Rev. Environ. Sci. Technol. 36 (2006) 1-84

[5] E. Guélou, J. Barrault, J. Fournier, J.M. Tatibouët, Active iron species in the catalytic wet peroxide oxidation of phenol over pillared clays containing iron, Appl. Catal. B 44 (2003) 1-8.

[6] R.M. Liou, S.H. Chen, M.Y. Hung, C.S. Hsu, J.Y. Lai, Fe (III) supported on resin as effective catalyst for the heterogeneous oxidation of phenol in aqueous solution, Chemosphere 59 (2005) 117-125.
[7] A. Rey, M. Faraldos, J.A. Casas, J.A. Zazo, A. Bahamonde, J.J. Rodríguez, Catalytic wet peroxide oxidation of phenol over Fe/AC catalysts: influence of iron precursor and activated carbon surface, Appl. Catal. B 86 (2009) 69-77.

[8] J.A. Zazo, J.A. Casas, A.F. Mohedano, J.J. Rodríguez, Catalytic wet peroxide oxidation of phenol with a Fe/active carbon catalyst, Appl. Catal. B 65 (2006) 261-268.

[9] J.A. Zazo, A.F. Fraile, A. Rey, A. Bahamonde, J.A. Casas, J.J. Rodríguez, Optimizing calcination temperature of Fe/activated carbon catalysts for CWPO, Catal. Today 143 (2009) 341-346.

[10] F. Lücking, H. Köser, M. Jank, A. Ritter, Iron powder, graphite, and activated carbon as catalysts for the oxidation of 4-clorophenol with hydrogen peroxide in aqueous phase, Water Res. 32 (1998) 2607-2614.

11] L.C.A Oliveira, C.N. Silva, M.I. Yoshida, R.M. Lago, The effect of $\mathrm{H}_{2}$ treatment on the activity of activated carbon for the oxidation of organic contaminants in water and the $\mathrm{H}_{2} \mathrm{O}_{2}$ decomposition, Carbon 42 (2004) 2279-2284.

[12] A. Rey, M. Faraldos, A. Bahamonde, J.A. Casas, J.A. Zazo, J.J. Rodríguez, Role of the activated carbon surface on catalytic wet peroxide oxidation, Ind. Eng. Chem. Res. 47 (2008) 8166-8174

[13] V.P. Santos, M.F.R. Pereira, P.C.C. Faria, J.J.M. Órfão, Decolourisation of dye solutions by oxidation with $\mathrm{H}_{2} \mathrm{O}_{2}$ in the presence of modified activated carbons, J. Hazard. Mater. 162 (2009) 736-742.

[14] E. Auer, A. Freund, J. Pietsch, T. Tacke, Carbons as supports for industrial precious metal catalysts, Appl. Catal. A: Gen. 173 (1998) 259-271.

[15] J.A. Menendez, J.J. Pis, Importance, characterization and modification of the surface chemistry of activated carbons, Review, Afinidad 55 (1998) 315-325.

[16] H.T. Gomes, B.F. Machado, A. Ribeiro, I. Moreira, M. Rosário, A.M.T. Silva, J.L. Figueiredo, J.L. Faria, Catalytic properties of carbon materials for wet oxidation of aniline, J. Hazard. Mater. 159 (2008) 420-426.

[17] H.T. Gomes, P.V. Samant, P. Serp, P. Kalck, J.L. Figueiredo, J.L. Faria, Carbon nanotubes and xerogels as supports of well-dispersed Pt catalysts for environmental applications, Appl. Catal. B 54 (2004) 175-182.

[18] H.T. Gomes, P. Serp, P. Kalck, J.L. Figueiredo, J.L. Faria, Carbon supported platinum catalysts for catalytic wet air oxidation of refractory carboxylic acids, Topics Catal. 33 (2005) 59-68.

[19] M.A. Ferro-García, J. Rivera-Utrilla, I. Bautista-Toledo, C. Moreno-Castilla, Adsorption of humic substances on activated carbon from aqueous solutions and their effect on the removal of $\mathrm{Cr}$ (III) Ions, Langmuir 14 (1998) 1880-1886.

[20] R.M. Smith, Understanding Mass Spectra: A Basic Approach, 2nd ed., John Wiley \& Sons, New Jersey, 2004.

[21] V. Alexéev, Análise Quantitativa, 3rd ed., Lopes da Silva Editora, Porto, 1983.

[22] J.L. Figueiredo, M.F.R. Pereira, M.M.A. Freitas, J.J.M. Órfão, Modification of the surface chemistry of activated carbons, Carbon 37 (1999) 1379-1389.

[23] J.L. Figueiredo, M.F.R. Pereira, M.M.A. Freitas, J.J.M. Órfão, Characterization of active sites on carbon catalysts, Ind. Eng. Chem. Res. 46 (2007) 4110-4115.

[24] A.P. Terzyk, Further insights into the role of carbon surface functionalities in the mechanism of phenol adsorption, J. Colloid Interface Sci. 268 (2003) 301.

[25] J.J.M. Órfão, A.I.M. Silva, J.C.V. Pereira, S.A. Barata, I.M. Fonseca, P.C.C. Faria, M.F.R Pereira, Adsorption of a reactive dye on chemically modified activated carbons influence of pH, J. Colloid Interface Sci. 296 (2006) 480-489.

[26] F. Rodríguez-Reinoso, The role of carbon materials in heterogeneous catalysis, Carbon 36 (1998) 159-175.

[27] P.C.C. Faria, J.J.M. Órfão, M.F.R. Pereira, Adsorption of anionic and cationic dyes on activated carbons with different surface chemistries, Water Res. 38 (2004) 20432052 . 